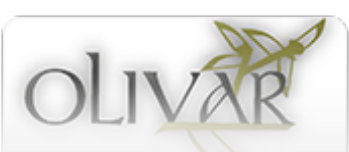

Olivar

ISSN: $1852-4478$

publicaciones@fahce.unlp.edu.ar

Universidad Nacional de La Plata

Argentina

\title{
Sabrina Riva, La garra suave: representaciones de Miguel Hernández como escritor popular, Salamanca, Ediciones Universidad de Salamanca, 2017, 259 pp.
}

\author{
Domingo, Mariano \\ Sabrina Riva, La garra suave: representaciones de Miguel Hernández como escritor popular, Salamanca, \\ Ediciones Universidad de Salamanca, 2017, $259 \mathrm{pp}$. \\ Olivar, vol. 19, núm. 30, 2019 \\ Universidad Nacional de La Plata, Argentina \\ DOI: https://doi.org/10.24215/18524478e068
}

Esta obra está bajo una Licencia Creative Commons Atribución-NoComercial-Compartirlgual 4.0 Internacional. 
Sabrina Riva, La garra suave: representaciones de Miguel Hernández como escritor popular, Salamanca, Ediciones Universidad de Salamanca, 2017, 259 pp.

Mariano Domingo

DOI: https://doi.org/10.24215/18524478e068

Universidad Nacional de Mar del Plata, Argentina

\author{
Soy una abierta ventana que escucha \\ por donde ver tenebrosa la vida. \\ Pero hay un rayo de sol en la lucha \\ que siempre deja la sombra vencida. \\ Miguel Hernández, "Eterna sombra”, Cancionero y romancero de ausencias
}

En La garra suave: representaciones de Miguel Hernández como escritorpopular de Sabrina Riva, el lector, sea un experto, un alumno en formación o un interesado casual en la trayectoria del poeta oriolano, se encontrará frente a un documentado estudio en torno de la peculiar figura del autor español. La especialista, conocedora de la vida y obra de Hernández, un emblema de la lucha republicana y sus ideales, revisa una serie de leyendas, homenajes y testimonios que han contribuido, con el transcurso de los años, a complejizar su imagen y legado. El diseño de tapa del volumen acompaña metafóricamente este recorrido: sobre un fondo azul oscuro y bajo el título en letras amarillas se ubica una reproducción multiplicada del conocido retrato hernandiano que el dramaturgo Buero Vallejo le hiciera en la cárcel madrileña de Conde de Toreno. De izquierda a derecha la imagen se difumina, pierde claridad, tiembla como si fuera sacudida. Lo mismo ocurre con las seguridades, los estereotipos, los cimientos sobre los cuales se ha afirmado históricamente cualquier intento de biografiar al poeta, revisados ahora bajo una nueva lente, se reconocen manidos e insuficientes para una cabal semblanza de un personaje tan singular y reconocido como Hernández.

Para llevar adelante su objeto, Riva se sirve de dos formaciones teóricas que sirven de pilares a toda su argumentación y que desarrolla en forma extensiva en el segundo apartado del primer capítulo del libro: por un lado, lo "popular", como categoría difícil de definir y en sus dinámicas relaciones de oposición y/ o negociación con la cultura hegemónica. Hernández, símbolo durante mucho tiempo del intelectual del pueblo, con un mitificado origen entre el ganado de su padre, un excéntrico ir y venir por Madrid y su paso a la inmortalidad a partir de lo hecho en y a posteriori de la guerra civil, se constituye en ejemplo del espesor de lo popular como categoría.

Por el otro lado, la cuestión de la "imagen de autor", es decir, la construcción de una representación particular del poeta, que se nutre no solo de sus propias palabras, aquello que se desprende de su pluma y de la predicación de sí mismo en versos, misivas y manifiestos, sino también de los discursos ajenos, de las diversas apropiaciones que se suscitan a lo largo y ancho del campo cultural y editorial, con una proliferación destacable en 2010, centenario de su nacimiento, ocasión más que propicia para su recuperación y reinterpretación en toda España. En ambos casos, para los dos conceptos trabajados, se registra una profusa cantidad de referencias bibliográficas que vale de apoyatura al razonamiento propuesto por la autora. Nombres tales como el de Foucault, Sarlo, Bourdieu, Bajtín, Gramsci, Chartier, García Canclini, Eco, entre otros ineludibles, se hacen lugar en un vasto entramado conceptual, que sin embargo resulta accesible a los lectores.

El capítulo segundo, "Miguel Hernández en su figura de escritor”, se abre con la mención de los “tres tristes tópicos” que supo delinear el biógrafo hernandiano Agustín Sánchez Vidal. El poeta pastor, el del pueblo y el 
del sacrificio son caracterizaciones que se replican constantemente, como marbetes, en las historias de vida de Miguel Hernández, pero también en otra clase de textualidades, así en las antologías infantiles, las novelas gráficas, las biografías en video, e incluso en la canción de autor, género que encuentra en el oriolano, en su obra y su experiencia vital, una gran fuente de inspiración. A partir de este punto, y a lo largo de todo el estudio, tales tópicos funcionarán a modo de herramientas para, en una primera instancia, indagar hacia adentro de las distintas modalidades textuales en las que Riva hace foco. Ahora bien, siguiendo la línea del propio Sánchez Vidal, que los plantea como caracterizaciones reductoras de la imagen de Hernández, en $L a$ garra suave, los mismos tópicos se ponen en cuestión, sus alcances se discuten y se descubren o proponen otras figuraciones posibles e igual problemáticas, como la del poeta niño, la del poeta soldado o la del poeta católico, que se desprende de las estrechas relaciones de Hernández con el canónigo Luis Almarcha durante su juventud.

En ese mismo segundo capítulo, la autora emprende el análisis de la trayectoria del oriolano en la escena literaria española, desde sus primeras apariciones públicas, de la mano de su amigo Carlos Fenoll en la prensa local a finales del 29, y posteriormente en los rotativos madrileños, a través de las escuetas menciones de Giménez Caballero y Martínez Corbalán. Es allí donde, entiende Riva, tiene origen el mito del poeta pastor del interior, que Hernández supo aprovechar una vez llegado a la capital. Esto le valió la simpatía inicial de ciertos intelectuales, algunos de la generación del 27, como García Lorca, pero también anteriores, como Juan Ramón Jiménez, con quienes mantuvo una correspondencia que el apartado registra y examina, apoyándose en la tarea de biógrafos hernandianos de la talla de Eutimio Martin, José Luis Ferris y el ya mencionado Agustín Sánchez Vidal.

Se refiere luego el nacimiento de la configuración de Miguel Hernández como poeta en fuerte conexión con la masa popular, el "poeta del pueblo", etiqueta que subsume, a la vez, la de "poeta soldado" y que tendría dos hitos fundantes. El primero, la mención de su nombre por parte del inglés Stephen Spender como ejemplo de poeta de la Guerra Civil española, durante el II Congreso de Internacional de Escritores Antifascistas de 1937. El segundo, un encendido preámbulo a su escrito "Fuerza del Manzanares", de Viento del pueblo, su magna obra de aquella época, termina de sellar un vínculo inexcusable con el bando republicano y sus partidarios, en una contienda que lo tendría como protagonista. Pero no un protagonista a medias, aclarará más adelante Riva, no un simple ideólogo de los de "mono azul" como Alberti y Aleixandre, sino un combatiente "con su cuerpo y con sus versos: las armas y las letras" (2017: 42).

Por último, con el tópico del "poeta del sacrificio" del que Miguel Hernández se cubrió ya fallecido en 1942, la autora hace lugar al sinfín de "leyendas y contraleyendas" que se urdieron alrededor suyo durante su experiencia carcelaria tras la derrota bélica. Algunas de ellas han llegado a comprobarse o se sostienen sobre algún substrato de verdad (las visitas de líderes falangistas a su celda), otras son negadas rotundamente (versos apócrifos como consignas escritas en las paredes de los presidios) y un tercer grupo se mantiene, aun para este estudio, bajo un manto de duda, lo cual no hace sino mantener vivo el misterio del hombre tras el símbolo, de una complejidad que se extiende más allá de cualquier tópico posible.

El capítulo, fundamental para el desarrollo posterior de la obra, se cierra con dos apartados. El primero de ellos se interesa por la escueta producción autopoética del oriolano, es decir, aquella que reflexiona metatextualmente sobre su práctica y proyecto estético. Riva destaca el conflicto bélico como el disparador principal de tal preocupación en Hernández, dado que previamente se registran solo unos pocos escritos de su tramo más formalista, aquel de Perito en lunas y parte de El rayo que no cesa. Otro factor importante para la transición hacia la poesía "rehumanizada" de Viento del pueblo, menos artificiosa, más ligada a la explosión del sentimiento no individual sino colectivo, es la amistad de Hernández con el chileno Pablo Neruda, de importante influencia en la escena lírica de la época en España. Su poemario, Residencia en la tierra, de 1935, tuvo un acusado impacto en la concepción del poeta de su propia tarea; la poesía, despojada de lastre estilístico formal, terminará por volverse un arma para la lucha y el autor, "viento del pueblo", se hace eco de 
sus denuncias, las esparce y reivindica así las ansias de justicia social por las que abogara la Segunda República, sobre todo en su etapa última.

En el apartado ulterior, "Reconstrucciones y representaciones de un ethos vital y poético", la autora lleva adelante un complejo trayecto a través de la diversidad de intentos por poner en palabras la experiencia de vida de un poeta quien, en palabras de Riva, "ha sufrido de un notorio hiperbiografismo" (2017: 51). Desde Miguel Hernández (1910-1942). Vida y obra, publicada por Concha Zardoya en 1955, hasta los estudios más recientes de José Luis Ferris, se revisa una gran variedad de propuestas, asociadas a distintas corrientes del quehacer autobiográfico, con trasfondos ideológicos disimiles y objetivos que van de la simple concatenación de los avatares de la vida del oriolano a la explicación de ésta por su obra, o la desarticulación de los ya mencionados tópicos, tan arraigados en el discurso alrededor de la figura Hernández. Por otro lado, no se limita el análisis a ejemplos de relato autobiográfico tradicional, sino que se incluyen también ejercicios más modestos, como la semblanza de Rafael Alberti, Imagen primera y definitiva de Miguel Hernández (1945) o aquella de Pablo Neruda "A Miguel Hernández asesinado en los presidios de España", parte de su poemario Canto general, de 1950.

El tercer capítulo de La garra suave comienza por indagar, en torno a la figura de Hernández, lo que Juan Cervera piensa en términos de "literatura ganada", es decir, aquellas obras que, en su génesis, no pertenecían al ámbito de la literatura pensada para niños, pero que paulatinamente fueron encontrando su lugar allí, adaptados o no, por acción de los adultos o interés de los propios destinatarios (Riva, 2017: 99-100). La primera referencia es a Miguel Hernández, para niños de Francisco Esteve Ramírez, publicado en 1980, incursión inicial de la biografía hernandiana en el imaginario infantil. Riva se interesa por la peculiar construcción del poeta oriolano que lleva adelante el antólogo al presentarlo ante un nuevo público, poco explorado por la pluma de Hernández, más atenta al trajín sociopolítico de su época que a cautivar a lectores en formación. Los tópicos de Sánchez Vidal se vuelven ineludibles para dar cuenta de la operatoria de Esteve Ramírez: Miguel Hernández, para niños antepone la imagen del "poeta pastor" y su variante "poeta niño", carente y autodidacta, más afines al lector previsto que la del "poeta soldado", comprometido, altavoz de la propaganda de la Segunda República española. El relato de su sacrificio termina por configurar el periplo idealizado, ejemplar de la vida de Hernández, quien a ojos del autor nunca habría dejado de ser un niño ni de apelar a la libertad, la sencillez, la inocencia, valores eminentemente asociados a esa etapa en la vida del hombre.

Posteriormente, Riva procede a comparar las propuestas de libros ilustrados para niños, que se multiplicaron con el centenario hernandiano. La naturaleza dual de estos textos complejiza su descripción, la matriz biográfica y poética del oriolano se funde con las imágenes en un nuevo vínculo significativo del que la autora procura dar cuenta, no solo mediante sus palabras sino también por la reproducción de algunos cuadros de cada volumen.

Los objetivos específicos que persigue cada biografía en particular no determinan únicamente la forma en que el autor es presentado, los hitos de su trayectoria que se privilegian, los tópicos empleados para su caracterización, las leyendas que subsisten en el relato, sino también la mediatización de éste por medio de las ilustraciones construidas. Un acercamiento como el de Rosa Navarro, el primero que aborda Riva, no soslaya la arista combativa consustancial a la vida del poeta, su tarea en el frente republicano, su fraternidad con los soldados, el sufrimiento posterior, y todo esto se ve reforzado por el componente iconográfico. Otros encuadres, en cambio, abogan por una imagen más inocente o angelizada del autor en su acercamiento al público infantil, se reduce o elide la carga política y bélica de su experiencia vital, lo cual repercute directamente en la faceta visual de la propuesta. Por último, el trabajo de José Luis Ferris, Miguel Hernández, pastor de sueños, viene a desautomatizar los lugares comunes de la biografía hernandiana con la entrada del elemento onírico, la superposición de hechos de la infancia y adultez, la lupa puesta sobre la escolarización del oriolano, todo esto sin desmerecer la labor política y combativa del "poeta del pueblo". 
A la biografía ilustrada le sigue su par en viñetas. El cómic o novela gráfica, con sus principios particulares, da lugar a manifestaciones tan disimiles como Me llamo barro de Díez y Navarro, reivindicación y crítica de la figura del "poeta pastor", en los lindes del libro-álbum, y Vida de Miguel Hernández. La voz que no cesa (2013) de Pereira y Boldú que, en las antípodas, parte de la experiencia carcelaria del biografiado para insistir, por un lado, en el axioma de la palabra como arma para la libertad y, por otro, en lo fundamentalmente trágico de la vida del oriolano. Ambas encuentran en la investigación de Riva un minucioso desarrollo, allí se explora la correlación de palabra e imagen que modela una u otra figura dentro de un personaje de tal complejidad como lo fue Hernández.

"La biografía televisiva y los mitos de la democracia" es el título del apartado que Riva dedica al análisis de aquellos relatos biográficos que trascienden lo escrito y llegan a la pantalla. La autora señala el mismo fenómeno de hiperbiografismo para ambos planos, sobre todo durante el aniversario ya referido, buena parte de las producciones que describe son de ese mismo año 2010. En los casos estudiados el interés documental predomina por sobre la ficción, los mojones en la existencia del oriolano anteceden a sus versos, citados en forma esporádica, ilustrativa, tautológica. Los documentales de la 2, por citar un ejemplo, serán fundamentales para la popularización de su imagen con la reinstauración de la democracia, para elevarlo, para regresarlo al Olimpo de las letras y la cultura española, tras ser silenciado desde su primer encarcelamiento, un silencio agravado por su comprobada negativa a retractarse de los ideales que alguna vez defendiera en el frente, con el cuerpo y la palabra. Miniseries televisivas y recreaciones paródicas completan un cuadro de lo más variado en lo que corresponde a las mediaciones entre la figura hernandiana y el cinematógrafo.

Los últimos dos capítulos previos a las conclusiones ponen en relación a Miguel Hernández con el acervo popular oral de la canción a través de un doble movimiento. Primero, se describe cómo el poeta supo adoptar elementos de lo folclórico a su escritura, por causa de su origen humilde, pero también por la influencia de toda la lírica escrita posterior que retoma aquellos, desde la tradición áurea hasta los mismos contemporáneos al oriolano, a quienes, por extensión, rinde culto. Desde sus comienzos, desde Perito en lunas y El rayo que no cesa, Hernández incorpora motivos de corte popular, a pesar de su predilección por las formas de arte mayor. El hiato de la guerra lo conduce a indagar en las posibilidades perlocutivas de la palabra a partir de la reelaboración de la tradición lírica popular. Viento del pueblo es resultado y medio de tales objetivos. Con el paso del tiempo, el repliegue hacia lo íntimo de El hombre acecha y, sobre todo, Cancionero y romancero de ausencias, da lugar a la entrada de la canción tradicional como género, a los metros cortos y la temática amoroso-afectiva. La autora analiza en detalle tales transiciones hacia dentro de la poética hernandiana.

Segundo movimiento, en "Miguel Hernández y la canción de autor", Riva explora las conexiones de su legado con la canción de autor española de los cincuenta, sesenta y setenta, continuadora de los propósitos de la poesía social y medio privilegiado para la denuncia de los excesos de una declinante dictadura franquista y de la posición condescendiente de los medios hegemónicos. Tras delinear los orígenes del género y contraponerlo a la canción comercial o gastronómica, el capítulo traza el derrotero de la poética y figura de Hernández por la discografía de cantautores y grupos de lo más heterogéneos, con especial énfasis en el caso de Joan Manuel Serrat, fundamental para la divulgación de la obra del poeta (Riva 2017: 221). Homenajes, versos, fragmentos o poemas íntegros reproducidos son relevados por la autora, todo lo cual termina por constatar el status de "poeta del pueblo" que supo asociarle Sánchez Vidal y que los artistas reivindican una y otra vez.

Bien podría asimilarse este movimiento ulterior del capítulo $\mathrm{V}$ de La garra suave al propósito que persigue el volumen en su conjunto: recuperar la imagen de Hernández como estandarte de la palabra popular con toda su complejidad, en la multiplicidad de testimonios que reavivan su mensaje y trascienden cualquier categoría reductora. La investigación de Riva supera entonces los marbetes teóricos, pone en correlación manifestaciones de lo más distanciadas y devuelve a la silueta hernandiana algo de la luz que supo tener y ofrecer mientras fuera ruiseñor de las desdichas. 
Olivar, 2019, 19(30), NoviEMBre, ISSN: 1852-4478

CC BY-NC-SA 